\title{
Language, Culture, and Identity Development in Adolescence: A Case Study of a Sixteen- Year-Old Multilingual Boy
}

JUNG HAN

HYEONG KYUN PARK

Purdue University

\begin{abstract}
A language learner has a complex social identity, which should be understood in a larger social context and interactions. The current study aimed to investigate the relationship between language and identity development through narrative inquiry. The participant of this case study is a sixteen-year-old Korean boy who speaks three languages and has been educated in the United States from kindergarten to high school. The study adopted narrative inquiry as the method, and interviews, observations, and journals were collected analyzed to produce the case story collaboratively. The results indicate that the child, who was exposed to multiple languages and raised by a family of immigrants, identifies himself in between different languages and cultures. Additionally, the linguistic and cultural identity of the participant was found to have influenced his heritage language maintenance. Finally, it was found that socio-cultural awareness of linguistic and cultural diversity impacted his multilingual competency during his adolescence.
\end{abstract}

Keywords: adolescence, bilingual, culture, identity, language, multilingual

\section{Introduction}

Investigating how to tap into the complex nature of students with different social backgrounds is critical for a successful and inclusive language education, especially for language minority students. The relationship between language and identity has always been one of the biggest issues in the second language education field. Norton and Toohey (2011) noted that "language learner's identities are always multiple and in process" (p. 437). She also posited that 
students who bring their language identities from different cultures need to be supported to construct positive identities under varying societal contexts (Norton \& Toohey, 2011).

According to poststructuralists, language is a tool for participating in specific language communities, and using language is a social and political practice (Ushioda \& Dörnyei, 2009). However, languages exist under power structures of society, and each language implies different power depending on who speaks it. Therefore, educators need to consider power relations between the language learners and native speakers since language learning and learner's identity construction are closely related (King, 2008).

This research is a case study of a sixteen-year-old Korean boy who has experienced US public school education. The main topics of this study were language, cultures, and children's identity development in adolescence.

\section{Research Questions}

How does exposure to different languages and cultures influence the identity of a multilingual child?

How and why does an immigrant child lose or maintain his heritage language and culture? How does a bilingual/multilingual child's socio-cultural awareness of linguistic and cultural diversity influence his multilingual competencies during his adolescence?

\section{Literature Review}

\section{Language and Language Ideology, and Identity Development}

Language, identity, and language ideologies are all intertwined in social contexts. Regarding language and ideology, Oriyama (2010) argued that schools are the most crucial institutions that reproduce social ideology and language hierarchy. According to Oriyama (2010), heritage language speakers' identities are developed through their L1 speeches, and their 
language uses reflect their desires to identify themselves. However, linguistic demands and requirements establish hierarchies in educational programs, and learners' heritage languages and cultural backgrounds are often not valued in the school context (Rojo, 2013). Additionally, a group with the dominant power also tend to establish a hierarchy that is beneficial to itself, which enables the identities of the dominant groups to be the norm while language minority groups are required to conform to the norm of the dominant group (Bucholtz \& Hall, 2004). In the U.S., the privileged status of English remains to be the dominant norm widely supported by society as minority language groups remain inaudible and invisible (Bucholtz \& Hall, 2004). Therefore, the identities of language minority students or second language learners are clearly different from that of mainstream learners in this society of inequalities (Darvin \& Norton, 2016). Since identity constructions of language learners are influenced by the power relationship in society, ignoring their identities would cause a negative impact on their second language learning (King, 2008).

\section{Language Minority Children's Identity}

Peirce (1995) argued that a language learner has a complex social identity, which indicates that social context and interaction are critical for language learner's identity formation. According to Bucholtz and Hall (2004), dominant ethnic group languages are positioned above minority group languages, and language minority children often feel disrespected and marginalized.

Regarding language and the immigrant status, investment in the target language is the investment in that society and the learner's identity at the same time. Mckay and Wong (1996) insisted that learners negotiate identities while they develop English skills. They remarked that limited English-speaking ability and the immigrant status are often regarded as difficulties in 
general abilities of an individual. However, the lack of fluency in English in second language learners does not translate to poor learning abilities. As Peirce (1995) argued, since a language learner and the learning context are closely related, we should consider the complex relationship of language learners to the target language and respect the immigrant learner's agencies while they are identifying, negotiating, and constructing their identities and developing a new language in the target language society.

\section{Heritage Language Speakers' Identities and Bilingual/Multilingual Competencies}

Heritage language speakers reflect their desire to identify themselves and develop their identities through their first language (L1) use. Therefore, bilingual/multilingual competency should be respected not just as an L2 (social dominant language) facilitator but also as the way of configuring their identities (Oriyama, 2010).

The ideology of racial, cultural, and linguistic superiority has a long history, and racism and linguistic intolerance are closely linked (Wiley \& Wright, 2004). According to Wiley and Wright (2004), historically, multilingual competency has been overlooked as an ability of peripheral language speaker, and bilingualism was not valued in our society to protect the interests of center speakers of English. However, students from different cultures and language backgrounds should be understood not as inferior but diverse, and we should value the rich linguistic backgrounds of English language learners (Wiley \& Wright, 2004).

\section{Method}

Based on the literature review, the current study further investigated the relationship between language and identity development through a narrative inquiry. "Narrative identity is a person's internalized and evolving life story, integrating the reconstructed past and imagined future to provide life with some degree of unity and purpose". Therefore, researchers adopted 
narrative inquiry to investigate the participant's personal stories told from young childhood to adolescence years, which reflect his meaning-making strategies in the process of his identity development (McAdams \& McLean, 2013, p. 233).

\section{Participant}

The participant was a sixteen-year-old Korean boy who has experienced US public school education- kindergarten to high school. At the time of the study, he was in eleventh grade attending a public high school located in a college town, where people from a variety of foreign countries live. When he was five years old, he and his middle class family moved to the U.S. from Korea. The participant spoke his first and second languages with high proficiencies. $\mathrm{He}$ achieved a TOPIK (Test of Proficiency in Korean) score in the highest category, which proved that his first langage proficiency was at the level of a native speaker's. Additionally, he was learning his third language, German, in high school. The participant had two younger siblings, who also spoke Korean and English. From now on, this participant will be noted with the pseudonym Jiho.

\section{Researcher Identity}

The first author is Jiho's mother, who has a master's degree in the Education department, majoring in Literacy and Language Education. The first author's undergraduate major was German Language and Literature, so she speaks Korean, English, and German. The first author was a bilingual teacher, who taught Korean immigrant children in Korean school. She also taught Korean in the International Center in the neighborhood of a large university.

\section{Data Collection}

All available data were collected for an in-depth qualitative study. The data were interviews, observations, participant's biography, and journals of the participant and the parent 
(first author). The researchers adopted narrative inquiry as the method as it has the potential for the researchers and the participant to produce the story collaboratively (Connelly \& Clandinin, 1990).

Interviews were conducted by the first author using English. The interview was semistructured. Based on the interview questions, the participant was asked to describe his story more in detail as needed. The interview questions consisted of Patton's (2015) interview questions types which include the questions of experience, behavior, opinion, values, feeling, and personal background.

Additionally, at the age of eleven in sixth grade, the participant created an autobiography that he had named as Years of Understanding as part of his school project. In this document, he recorded all about him from birth to sixth grade based on interviews with family and relatives, his journals, and his memories.

The interview analysis followed three steps of process, which included coding, categorizing, and reorganizing, to find important features to be discussed. Interviews were transcribed, and the words and sentences related to identity, culture, language, minority, and social interaction were coded and categorized as a positive or negative influence on language identity and learning. For example, the comment, "Korean is not really a popular language", was coded as LMFN (Language-Minority-Opinion-Negative) while "The United States has a really nice culture including aspects such as diversity and acceptance" was coded as CDOP (CultureDiversity-Opinion-Positive). Coding and emerging themes were crosschecked by the first and second authors. Journals and documents from kindergarten to high school years of the subject were also used as data. The journals and biographies of the participant were analyzed in the same 
way as the interview analysis, which followed the proceess of coding, categorizing, and reorganizing. Same codes were used for interviews, participant's biography, and journals.

Based on the data analysis and literature review, the researchers selected meaningful findings, which can be applied to current identity theories that are influential in Second Language Studies.

\section{Results}

\section{Multilingual Adolescent's Identity Negotiation}

Jiho was born in South Korea and moved to the U.S. when he was five years old. In his middle-class family, he has two younger siblings, and as the first child in the family, Jiho had a strong sense of responsibility. His favorite hobby was soccer since the time he was in Kindergarten. The autobiography revealed how he felt about his relationship with others, the influence of family and friends, and the difficulties he experienced from his language barrier. In one of the chapters, he described his fourth-grade period as his Dark Age.

This (fourth-grade) was the year where I've been doing terrible things. I bragged, cried, and failed every test I've taken. I even fought with somebody over a friend! But my teacher never punished me in a harsh way... While fourth grade could have been my worst year, I was able to set an example for myself to not repeat (Autobiography, $6^{\text {th }}$ grade).

A significant memory from the first author regarding the above quote was that all the people that Jiho had troubles with were from immigrant families. This reflects how a language minority student's identity construction is influenced by the power relationship in the society (King, 2008). Since Jiho did not belong to the mainstream group, he demonstrated his struggles with peers from immigrant families like himself, which indicates that he conceded to the idea that he 
belong to the group with cultures of minorities. Jiho was trying to construct his identity and be recognized by others in the new society, but he often revealed his struggles to those who were in the same situation as him.

Reflecting on the first author's memory and journals, Jiho had a high spirit to submit to another. He was smart and hardworking in everything, but when he felt that he was despised or neglected, he often revealed his frustrations. Jiho confessed in his autobiography that back when I was in kindergarten through fourth grade, I bragged to a lot of people for being smart, such as knowing multiplication in kindergarten, division in first grade, fast arithmetic skills in second grade, fractions in third grade, and so on. Those days I thought that I was doing better than anyone in the school. Well, as I look back now to what I was doing in fifth grade, I realize I wasn't even doing all that great in school my worst year, I was able to set an example for myself to not repeat (Autobiography, $6^{\text {th }}$ grade).

The above narrative demonstrates the efforts of Jiho to demonstrate his identity as not marginalized or inferior but rather superior to other children. As Wiley and Wright (2004) noted, the ideology of racial, cultural, and linguistic superiority permeated into our society, and children from different cultures and language backgrounds are often regarded as inferior.

When Jiho entered his adolescence, he struggled to find his identity like his peers. He described how he thought about his own personality in the interview.

Um, my personality ... I'm really impatient sometimes and I um, have a really bad tendency to get really angry at something or sad about something. So, my personality, I guess, is that I get really impatient sometimes and am emotional. It's something that has been worse in earlier years (Interview, $11^{\text {th }}$ grade). 
As noted in the above quote, Jiho described his unstable emotions and mixed feelings like his peers. However, the following quote also reveals his struggle to construct and negotiate his identity in specific socio-cultural, racial, and family relationships.

I'm not $100 \%$ proud of my racial identity, but I'm mostly proud of it, because Koreans have a really good reputation for being smart, hard-working... and so on... my dad wants me to focus more on my academics when I try to sign up for a soccer team. I really like soccer, and I do care about my academics. My dad sometimes doesn't trust me sometimes on whether I would be able to juggle everything. And, um, we get into few arguments because he does not trust me. Hopefully, he could become more supportive of the decisions I make even though I understand his intentions (Interview, $11^{\text {th }}$ grade).

Notably, Jiho had a strong awareness of his ethnicity and language. He spoke only Korean at home and was often upset whenever he heard his younger siblings speaking in English at home. He said that Koreans should be able to speak Korean. This opinion was influenced by his parents, who allowed only Korean at home. However, on top of his parents' rule, Jiho also liked his heritage culture, history, and language. He was familiar with Korean literature and history, watched Korean movies and drama, and communicated with Korean friends through a Korean social network service system. Furthermore, he described in his journal that his trip to Korea in sixth grade as the best memory. He confessed in the interview:

There are a lot of places I want to live in, but I want to live in Korea because that is where I was born and where I feel most comfortable. I love a lot of things about Korea, so I would want to live there... Korean is not really a popular language compared to Chinese, English, Spanish... It is not as popular, but it is getting there. For Korean culture, some representative aspects are K-pop, which is really famous internationally. 
The food is really nice, that's for sure. Um, respect is a big part of our culture... I can honestly say a lot more about the Korean culture my worst year, I was able to set an example for myself to not repeat (Interview, $11^{\text {th }}$ grade).

As described above, his interest in his culture and language helped him maintain his heritage language. Oriyama (2010) pointed out that identity and identification influence a bilingual's language ability because both factors influence the functions and the degree of language use of the individual (p. 78).

\section{Language and Identity}

Language speakers produce and reproduce their particular identities continually through their language use (Bucholtz \& Hall, 2004). However, When Jiho first came to the U.S at the age of five, he was shocked not only at the cultural difference but also at the fact that he was not able to communicate with his teacher and the classmates. His autobiography describes what he felt at the time:

I was ready for America! I learned a lots and lots of English in Korea, and I believed that I would be able to communicate with the people...However, I was terrified by how intense it was to talk to my teacher and my new classmates when I came to my elementary school! I was so stressed that I wanted to quit and go back to Korea. I thought

I wouldn't be able to survive school! (Autobiography, $6^{\text {th }}$ grade)

As Jiho has described, he found himself embarrassed in the new situation that was completely different from where he came from. Under this circumstance, Jiho confronted difficulties in interaction with people who use English as their first language. Peirce (1995) argued that there are "complex relationships between power, identity, and language learning" (p. 17). According to her, language learners have complex social identities, and target language learners continually 
construct a sense of who they are and how they relate to their societies. McKay and Wong (1996) conceptualized the second language learners as complex social beings and noted that understanding the power issues in second language learning is critical in examining how second language learners negotiate multiple discourses in which they are situated.

Within linguistics, differences construct hierarchy, and the group with the greater power constitutes itself as the norm. Researchers termed this hierarchical structuring as 'markedness' and argued that marked identities are ideologically associated with marked language (Bucholtz \& Hall, 2004). From the interview, Jiho expressed difficulties he felt as a foreigner.

Certainly, there are difficulties...There's a lot of segregation and discrimination that happens anywhere, so I guess there are difficulties there. There's no such thing as no difficulties as international (people) since it is difficult for them to adapt to the foreign country (Interview, $11^{\text {th }}$ grade).

Jiho's feeling about difficulties may relate to what Bucholtz and Hall (2004) noted about the process to conform to the norm of the mainstream society. Bucholtz and Hall (2004) posited that speakers cannot disregard existing linguistic and social norms, which constrain speakers who resist and subvert social inequalities.

\section{Language and Investment}

Jiho spoke three languages, Korean, English, and German. He said he liked learning languages and exploring diverse cultures of societies where the languages are used.

Well, I really enjoy learning languages and diverse cultures, although I don't know a lot of them...think I'm doing pretty well on it ... German culture, um, there is a lot of food and historic sites. They have a fantastic culture. The United States has a really nice culture including aspects such as, um, diversity and acceptance... I do want to learn more 
languages if I can. I have a lot of languages that I am interested in, including Japanese, Chinese, French... and also Spanish. I want to learn all of them, but the problem is the time. If I happen to find spare time, I would be able to learn a few languages (Interview, $11^{\text {th }}$ grade).

Jiho's comment above shows his interest in languages and cultures, which is reinforced by his mentioning of diversity and acceptance. However, unlike Jiho, most of his Korean friends did not use their native language inside and outside of their homes. When the first author asked Jiho how he thought about his Korean friends and their families' language uses and attitudes, he answered;

Well, I have a lot of Korean friends and families because we are next to a University that many Asian people apply to. A lot of my Korean friends have been like living here for like almost their entire life. Some people were just born here. One of them has never been to Korea until like two years ago. I went with him and hung out with him in Gangnam, a place in Seoul, and um, as I watched him speak Korean to Korean people, I noticed that he wasn't really fluent. That was obvious because he did not know how to speak it until he came to Korea that year for the first time. What I thought after seeing that was that Koreans who are born here or have lived here for a really long time put less effort into learning the language because it's technically useless in knowing the language while living in the United States. I feel like, um, they don't really care about learning and getting better at the language (Interview, $11^{\text {th }}$ grade).

As Jiho commented, people who live in the United States, where English is the dominant language, may not feel the necessity to invest in learning other languages, let alone even their heritage languages. According to Lam (2004), language learning is "an important social practice 
through which a society constructs and reproduces its dominant beliefs, values, and social relations" (p. 44). Therefore, language minority people feel that their heritage languages may not be valued enough for them to invest their efforts into them.

\section{Discussion and Limitations}

The current study was guided by three research questions. For the first question, How does exposure to different languages and cultures influence the identity of a multilingual child?, Jiho identified himself as in between different languages and cultures. He showed that he was positioned in diverse cultures while exposed to multiple languages. Even though this experience created difficulties for him as a minority student within the mainstream society, it also positively influenced his multilingual competency. As he noted, diversity and acceptance were critical for foreign language learning and his heritage language maintenance.

For the second research question, How and why does an immigrant child lose or maintain his heritage language and culture?, individual effort with strong will to maintain one's heritage language seems critical. Jiho worked hard to learn his culture and language unlike his other immigrant friends. As Jiho noted, many immigrant children may have felt that their heritage languages are useless in a dominant language society, which lead to the loss of their first languages.

For the third question, How does a bilingual/multilingual child's socio-cultural awareness of linguistic and cultural diversity influence his multilingual competencies during his adolescence?, Jiho's awareness of cultural and linguistic diversity seemed to critically affect his language learning. As indicated in the response to the first and second research question, acceptance of cultural diversity and respect for diverse languages may influence language learner's bilingual or multilingual competencies. 
As we see from Jiho's case example, along with individual difference, social norms played an important role throughout his identity development. Under the society that reproduces social inequalities, language minority students may conceive themselves differently from that of mainstream learners.

Jiho also showed that motivation, investment, and social ideology played critical roles during his identity development and language learning. Language is in the center of identity formation, and diverse discourses have effects on language learners' identity negotiation (McKay \& Wong, 1996). According to Bucholtz and Hall (2004), "identity is constructed through a variety of symbolic resources, especially language" (p. 370).

Language learning is not only developing learners' linguistic fluencies but also developing multiple and sophisticated identities in the target language society. Therefore, educators need to be aware of language learners' complex social identities, which should be understood in a larger social context and social interaction, in order to support them build positive identities (Peirce, 1995).

The current study has some limitations. First, this case involved only one participant, which makes the generalizability and applicability of the study to other cases questionable. Additionally, considering the close relationship between the subject and the first author as a son and a parent, the participant's response to the interview questions may not indicate his candid understanding of himself in front of the researcher's presence. However, the study does have some valuable implications. It summarizes the participant's identity formation from kindergarten to his high school years, which indicates the participant's reflection about his entire process of identity formation. The case study suggests that in order to support not only language learning 
but also positive identity formations, we need to create school contexts and communities around the learners who value diverse language and cultures.

\section{Conclusion}

Identity research involves the exploration of various people in a diverse society. A person's identity does not influence only his or herself but also the other people individually and socially. Also, language development is influenced by whether or not the social context is respectful of the linguistic, cultural, and racial diversity. This case study indicates that language identity is influenced by multiple factors such as personality, personal value, motivation, and social relationship. Therefore, we should provide a context where children can develop their personal and social identities appropriately in the respectful climates, regardless of their sociocultural statuses, language uses, and cultural diversities.

\section{ABOUT THE AUTHORS}

Ms. Jung Han is a doctoral candidate of Engineering-Technology Teacher Education in the department of Technology, Leadership, and Innovation at Purdue University. Her research interest is engineering design-based integrated STEM education for underrepresented students.

Mr. Hyeong Kyun Park is an undergraduate student in Computer Science at Purdue University. He has interests in language and cultural diversities and has contributed to the paper as a second coder and by conducting the literature review.

Inquiries can be directed to Jung Han at: han336@purdue.edu

\section{References}

Bucholtz, M., \& Hall, K. (2004). Language and identity. A Companion to Linguistic Anthropology, 1, 369-394. 
Connelly, F. M., \& Clandinin, D. J. (1990). Stories of experience and narrative inquiry. Educational Researcher, 19(5), 2-14. doi: 10.3102/0013189X019005002

Darvin, R., \& Norton, B. (2016). Investment and language learning in the 21 st century. Langage et société, (3), 19-38.

King, B. W. (2008). "Being gay guy, that is the advantage": queer Korean language learning and identity construction. Journal of Language, Identity, and Education, 7(3-4), 230-252. doi: $10.1080 / 15348450802237855$

Lam, W. S. E. (2004). Second language socialization in a bilingual chat room: Global and local considerations. Language Learning \& Technology, 8(3), 44-65. doi: 10125/43994

McAdams, D. P., \& McLean, K. C. (2013). Narrative identity. Current Directions in Psychological Science, 22(3), 233-238. doi: 10.1177/0963721413475622

McKay, S. L., \& Wong, S. L. C. (1996). Multiple discourses, multiple identities: Investment and agency in second-language learning among Chinese adolescent immigrant students. Harvard Educational Review, 66(3), 577-609. doi:

10.17763/haer.66.3.n47r06u264944865

Norton, B., \& Toohey, K. (2011). Identity, language learning, and social change. Language teaching, 44(4), 412-446. doi: 10.1017/S0261444811000309

Oriyama, K. (2010). Heritage Language Maintenance and Japanese Identity Formation: What Role Can Schooling and Ethnic Community Contact Play? Heritage Language Journal, 7(2), 76-111.

Patton, M. Q. (2015). Qualitative Research \& Evaluation Methods (4th ed.). Thousand Oaks, CA: SAGE.

Peirce, B. N. (1995). Social identity, investment, and language learning. TESOL Quarterly, 29(1), 9-31. doi: 10.2307/3587803 
Rojo, L. M. (2013). Capitalising students through linguistic practices: A comparative analysis of new educational programmes in a global era. In A. Duchêne, M. Moyer \& C. Roberts (Eds.), Language, migration and social inequalities: a critical sociolinguistic perspective on institutions and work (pp. 118-146) Bristol: Multilingual Matters.

Ushioda, E., \& Dörnyei, Z. (2009). Motivation, language identities and the L2 self: A theoretical overview. Motivation, language identity and the L2 self, 2, 1-8.

Wiley, T.G., \& Wright, W.E. (2004). Against the Undertow: Language-Minority Education Policy and Politics in the "Age of Accountability". Educational Policy, 18(1), 142-168. doi: $10.1177 / 0895904803260030$ 